\title{
ALTERNATIVAS DE ARMAZENAMENTO E ABASTECIMENTO DE ÁGUA EM ASSENTAMENTOS RURAIS DO SEMIÁRIDO ALAGOANO
}

\author{
Élida Monique da Costa Santos \\ Universidade Federal de Alagoas, Instituto de Geografia, Desenvolvimento e Meio Ambiente, \\ Maceió, AL, Brasil \\ elidamoniquecs@outlook.com
}

Kallianna Dantas Araujo

Universidade Federal de Alagoas, Instituto de Geografia, Desenvolvimento e Meio Ambiente, Pós-Graduação em Geografia, Maceió, AL, Brasil kallianna.araujo@igdema.ufal.br

Mayara Andrade Souza Centro Universitário CESMAC, Pós-Graduação em Análise de Sistemas Ambientais, Maceió, AL, Brasil mayarandrade@hotmail.com

Danúbia Lins Gomes

Universidade Federal de Alagoas, Instituto de Ciências Biológicas e da Saúde, Pós-Graduação em Diversidade Biológica e Conservação nos Trópicos, Maceió, AL, Brasil dlinsgomes@yahoo.com.br

Ana Paula Lopes da Silva Universidade Federal de Alagoas, Instituto de Geografia, Desenvolvimento e Meio Ambiente, Pós-Graduação em Geografia, Maceió, AL, Brasil

lakes br@yahoo.com.br

Elba dos Santos Lira Universidade Federal de Alagoas, Instituto de Geografia, Desenvolvimento e Meio Ambiente, Maceió, AL, Brasil elbaslira@yahoo.com.br

Leila Caroline Salustiano Silva Universidade Federal de Alagoas, Instituto de Geografia, Desenvolvimento e Meio Ambiente, Maceió, AL, Brasil leila-caroline@hotmail.com

João Gomes da Costa Centro Universitário CESMAC, Pós-Graduação em Análise de Sistemas Ambientais, Maceió, AL, Brasil joao-gomes.costa@embrapa.br

\begin{abstract}
RESUMO
A região Semiárida caracteriza-se por apresentar alta variabilidade no sistema hidrológico, forçando os moradores a utilizar mais de uma fonte de água durante o período de estiagem. Objetivou-se identificar as alternativas de armazenamento e abastecimento de água utilizada em Assentamentos Rurais do Semiárido de Alagoas. Foram aplicados 140 questionários aos moradores dos Assentamentos Nova Esperança (Olho D’Água do Casado) e Maria Bonita (Delmiro Gouveia), para obter informações sobre formas de armazenamento, fonte de água e abastecimento domiciliar. A principal fonte de abastecimento de água nos Assentamentos Nova Esperança e Maria Bonita é o rio São Francisco, no entanto a água recebida é sem tratamento, pois a maioria dos moradores não utilizam a água fornecida pela CASAL. Nos dois Assentamentos a maioria da população armazena água em cisternas. Mesmo com água encanada em casa, os moradores fazem uso de carro-pipa para complementar o abastecimento domiciliar, notadamente no período de estiagem. Uma forma de minimizar os problemas causados pela seca no Semiárido Alagoano é tornar uma área inutilizada em um local próprio para captação e armazenamento de água pluvial de uso comunitário. Sugere-se a realização de testes físicoquímicos e biológicos da água para análise da qualidade da mesma recebida pelos moradores.
\end{abstract}

Palavras-chave: Caatinga. Cisternas. Período de estiagem. Rio São Francisco. Região Semiárida. Sistema hidrológico. 
Alternativas de armazenamento e abastecimento de água em assentamentos rurais do semiárido alagoano
Élida Monique da Costa Santos; Kallianna Dantas Araujo;

Mayara Andrade Souza; Danúbia Lins Gomes;

Ana Paula Lopes da Silva; Elba dos Santos Lira; Leila Caroline Salustiano Silva; João Gomes da Costa

\title{
ALTERNATIVES OF WATER STORAGE AND SUPPLY IN RURAL SETS OF THE SEMI-ARID
}

\begin{abstract}
The semi-arid region is characterized by high variability in the hydrological system, forcing residents to use more than one water source during the dry season. The aim of this study was to identify the storage and water supply alternatives used in Rural Settlements in Semi-arid of Alagoas. 140 questionnaires were applied to residents of Nova Esperança Settlements (Olho D’Água do Casado) and Maria Bonita (Delmiro Gouveia) to obtain information on ways of storage, water supply and household supply. The main source of water supply in Nova Esperança and Maria Bonita Settlements is São Francisco river, however the water received is untreated, since most residents do not use the water supplied by CASAL. In both settlements the majority of the population stores water in cisterns. Even with tap water at home, residents use a car kite to supplement home supply, notably during the dry season. One way to minimize the problems caused by the drought in Alagoan Semi-arid is to make an unused area in a place suitable for collecting and storing rainwater for community use.It is suggested to perform physical-chemical and biological tests of the water to analyze the quality of the same received by the residents.
\end{abstract}

Keywords: Caatinga. Cisterns. Dry Season. São Francisco River. Semi-arid Region. Hydrological system.

\section{INTRODUÇÃO}

A água é uma temática que atualmente vem sendo discutida mundialmente. Sua escassez promove a procura por fontes alternativas de abastecimento e armazenamento, visando tornar seu uso racional. Sendo relevante não apenas para as regiões onde há um longo período de estiagem, bem como para assegurar um fornecimento estável da mesma, garantindo melhores condições para a população e gerações futuras. Em muitas regiões Áridas e Semiáridas do mundo, quando as demais formas de obtenção de água já estão escassas, a coleta de água da chuva é realizada como única forma de obtenção desse recurso natural (NADDEO et al., 2013). No entanto, como a região Semiárida é caracterizada por apresentar alta variabilidade da precipitação pluvial, com períodos de estiagem que duram entre 5 e 9 meses que tendem a se repetir de forma inter e intra anual, a disponibilidade hídrica nesta região acaba ficando comprometida, já que a precipitação média anual corresponde a $500 \mathrm{~mm}$ (DRUMOND, 2012), havendo também anos com totais abaixo das médias históricas (MARENGO et al., 2011).

Sampaio (2010) menciona que a disponibilidade hídrica é limitada e variável no tempo e espaço, decorrente da variabilidade da precipitação pluvial, ocorrendo períodos chuvosos intercalados irregularmente com períodos de secas. Além disso, o relevo presente nas regiões Semiáridas, caracterizados por Encostas, Serras e Chapadas, influenciam diretamente na interceptação das chuvas, auxiliando na formação de lagoas e rios intermitentes, contribuindo para a disponibilidade de água por um período mais longo. Cabe destacar que nessas áreas os solos apresentam diferentes texturas e profundidades, com variação na capacidade de retenção das águas pluviais. Marengo (2008) afirma que a irregularidade das chuvas e o limitado sistema eficiente de armazenamento da água, é um obstáculo frente ao desenvolvimento das atividades no Semiárido. Em escala global, em regiões com clima Árido e/ou Semiárido, os problemas gerados pelas secas para a população rural são similares. No Semiárido brasileiro as secas prolongadas afetam milhões de pessoas, dizima animais e compromete a agricultura, provocando um colapso socioeconômico (SANTOS et al., 2009). Diante deste contexto, elaborou-se o seguinte questionamento: quais as alternativas de armazenamento e abastecimento de água utilizada em Assentamentos Rurais do Semiárido de Alagoas? Para responder esta indagação foi elaborada a hipótese: nas regiões Semiáridas, notadamente nos municípios Alagoanos Olho D'Água do Casado e Delmiro Gouveia, a principal fonte de abastecimento de água é o rio São Francisco, no entanto, mesmo com a proximidade do rio, a população ainda fica vulnerável à

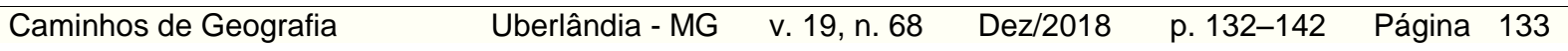


Alternativas de armazenamento e abastecimento de água em assentamentos rurais do semiárido alagoano
Élida Monique da Costa Santos; Kallianna Dantas Araujo; Mayara Andrade Souza; Danúbia Lins Gomes; Ana Paula Lopes da Silva; Elba dos Santos Lira; Leila Caroline Salustiano Silva; João Gomes da Costa

escassez de água, já que os moradores tem baixo poder aquisitivo e há um alto custo para recebimento da água encanada em suas residências. Devido à variabilidade hídrica existente na região, o abastecimento também se dá mediante utilização de água armazenada em cisternas. Além das dificuldades de abastecimento e armazenamento de água nesses Assentamentos rurais, destacam-se também problemas que possivelmente estejam relacionados com a qualidade da água, pois, a população não recebe o sistema de água potável tradicional, onde é feito um tratamento antes do abastecimento domiciliar, de modo que a manutenção da qualidade da água é feita pelos próprios moradores mediante seu conhecimento empírico. Contudo, devese destacar que, embora em algumas situações, a quantidade de água armazenada pelas cisternas seja suficiente para suprir as necessidades básicas da comunidade na época de estiagem, esta água normalmente está fora dos padrões de potabilidade (AL SALAYMEH et al., 2011). Neste sentido, o presente estudo apresenta elevada importância no contexto social e acadêmico, visto que o mesmo aborda um tema atual e pertinente para a população de regiões Semiáridas que, comumente, enfrentam problemas relacionados à disponibilidade de água, devido à irregularidade das chuvas que variam ao longo dos anos, dificultando ainda mais o abastecimento hídrico nessas regiões.

Desse modo, o presente trabalho objetiva identificar as alternativas de armazenamento e abastecimento de água utilizada em Assentamentos Rurais do Semiárido de Alagoas. Foi verificado que a principal fonte de água utilizada pela população nos dois municípios é o rio São Francisco e que muitos moradores ainda não receberam a doação de cisternas pelo Governo Federal. Cabe destacar que parte da população tem acesso à água encanada, embora no período de estiagem prolongada não seja suficiente para atender a demanda da população local . Nesse sentido, é necessária a procura pelo abastecimento mediante carro pipa, tornando-se oneroso para a população, forçando a mesma a buscar por fontes alternativas de abastecimento de água, notadamente nos últimos cinco anos, quando o período de escassez hídrica se intensificou na região. Como uma parte dos moradores não tem possibilidade de armazenar grande quantidade de água em casa, uma forma de minimizar os problemas causados pela estiagem prolongada no Semiárido Alagoano é tornar uma área inutilizada em um local próprio para captação e armazenamento de água pluvial de uso comunitário.

\section{MATERIAL E MÉTODOS}

\section{Caracterização territorial das áreas de estudo}

A pesquisa foi realizada nos municípios Olho D'Água do Casado e Delmiro Gouveia, inseridos na Mesorregião Geográfica do Sertão Alagoano e Microrregião Geográfica Alagoana do Sertão do São Francisco (Figura 1). O município Olho D’Água do Casado localiza-se nas coordenadas geográficas $10^{\circ} 03^{\prime} 30^{\prime \prime} \mathrm{S}$ e $36^{\circ} 49^{\prime} 00^{\prime \prime} \mathrm{O}$, com altitude de $230 \mathrm{~m}$ (ALAGOAS, 2015), na região Oeste do Estado de Alagoas, limitando-se a Norte com os municípios de Inhapi e Água Branca, ao Sul com o rio São Francisco, a Leste com Piranhas e a Oeste com Água Branca e Delmiro Gouveia (MENDONÇA e SIMÕES, 2012) (Figura 1). A Sede do município Delmiro Gouveia está

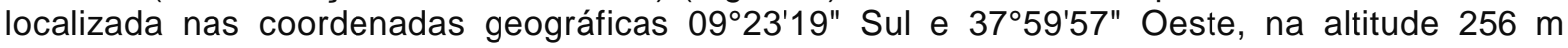
(ALAGOAS, 2015). Encontra-se no extremo Oeste do Estado de Alagoas, limitando-se a Norte com os municípios de Pariconha e Água Branca, ao Sul com o rio São Francisco, a Leste com Olho D'Água do Casado e a Oeste com os Estados da Bahia e Pernambuco (MENDONÇA e SIMÕES, 2012) (Figura 1).

O clima das áreas é BSh - Tropical Semiárido, segundo Köppen (LIMA, 1977) com período chuvoso de novembro a abril (MASCARENHAS et al., 2005ab). Olho D'Água do Casado dispõe de precipitação pluvial de 545,6 mm/ano, temperatura do ar média anual de $25,6{ }^{\circ} \mathrm{C}$ e umidade relativa de $74,4 \%$. Em Delmiro Gouveia a precipitação pluvial corresponde a $512,1 \mathrm{~mm} / \mathrm{ano}$, temperatura do ar de $25,5^{\circ} \mathrm{C}$ e umidade relativa de $74,4 \%$ (UFCG, 2017). 
Alternativas de armazenamento e abastecimento de água em assentamentos rurais do semiárido alagoano
Élida Monique da Costa Santos; Kallianna Dantas Araujo;

Mayara Andrade Souza; Danúbia Lins Gomes;

Ana Paula Lopes da Silva; Elba dos Santos Lira; Leila Caroline Salustiano Silva; João Gomes da Costa

Figura 1: Localização dos municípios Olho D’Água do Casado e Delmiro Gouveia, Microrregião Geográfica Alagoana do Sertão do São Francisco.

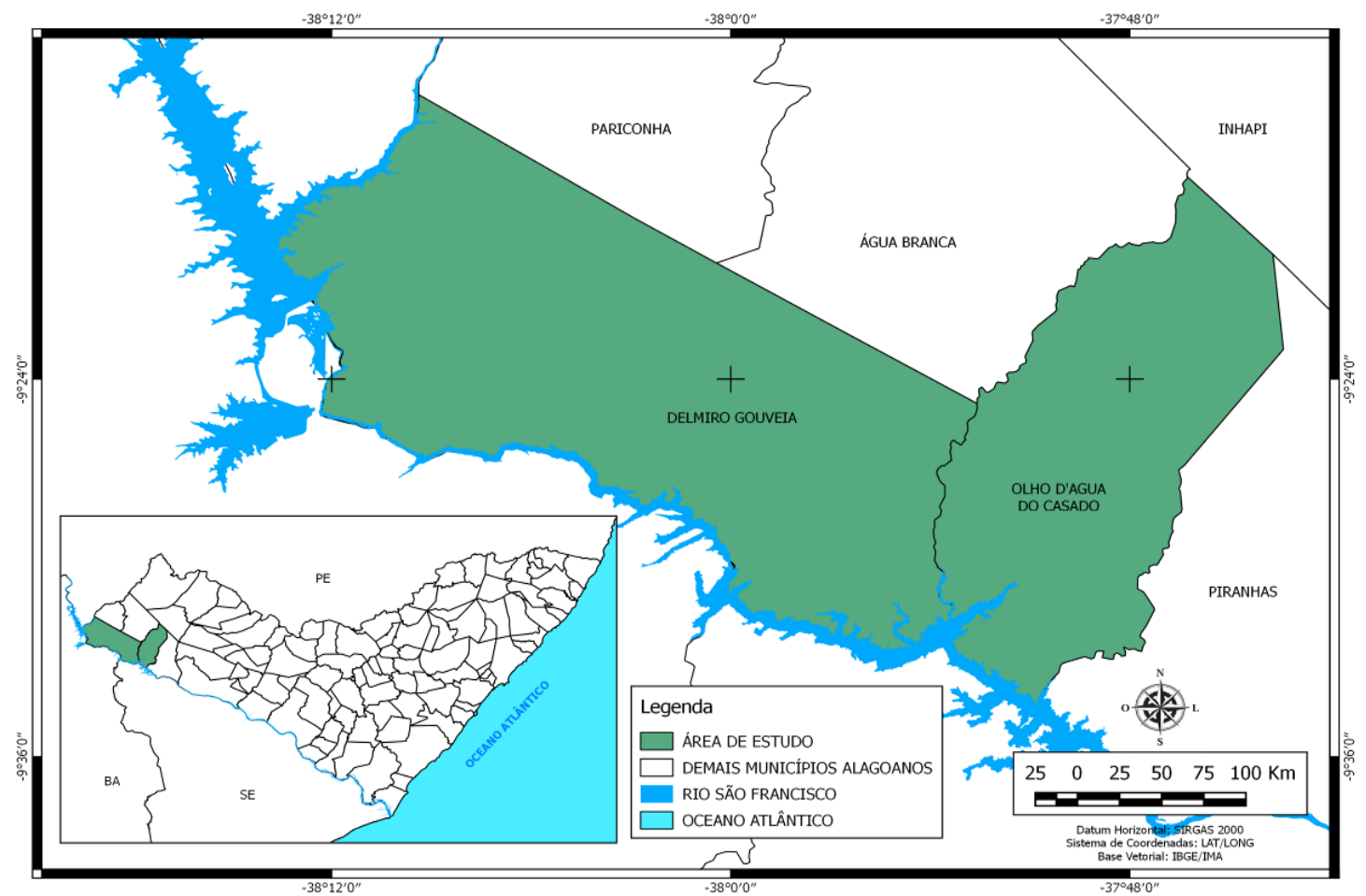

Fonte: SANTOS (2015)

Os municípios estão inseridos na bacia hidrográfica do rio São Francisco, cujo padrão de drenagem predominante é Pinado, uma variação do Dendrítico (MASCARENHAS et al., 2005ab) (Figura 2). Em Olho D'Água do Casado todos os afluentes e sub-afluentes são intermitentes. Seus principais tributários são os riachos Seco, Pombas, Maniva, Barracas, Pia do Gato, Mangote, Talhado, Águas Mortas, Velho e Porcos. O sistema fluvial deságua no rio São Francisco (MASCARENHAS et al., 2005a). Delmiro Gouveia é banhado apenas por tributários secundários da sub-bacia do rio do Maxixe, que atravessa a Sede do município. Os principais tributários são: riachos Salinas, Olaria, Curral Novo, Correia, Mortes, Cachoeira, Salgadinho, Ripa, Lajedinho, Pereira, Cordeiro, Grota Funda, Grande da Cruz, Barriguda, Salgado, Veneza, Xingó, Areia, Castanho, Juremas, Olho D’Água, Bom Jesus, Cachoeirinha e Talhado (MASCARENHAS et al., 2005b).

Os solos predominantes em Olho D'Água do Casado são Planossolos, de fertilidade natural média, ocorrendo principalmente nas áreas de patamares elevados e relevo suave ondulado. Nos topos e vertentes, os solos predominantes são Luvissolos (rasos e de fertilidade alta) e Argissolos (fertilidade natural média). Os Neossolos (rasos, pedregosos e de fertilidade natural média) ocorrem nos locais de maciços residuais (EMBRAPA, 2012). Em Delmiro Gouveia, os solos que pedominam são Neossolos Litólicos e Neossolos Regolíticos, constituídos de fragmentos pedregosos, apresentando-se rasos com textura de média a arenosa. Ocorrem também, em menor extensão, os Neossolos Flúvicos, correspondendo aos sedimentos que são depositados nos ambientes de várzeas (EMBRAPA, 2012). 
Alternativas de armazenamento e abastecimento de água em assentamentos rurais do semiárido alagoano
Élida Monique da Costa Santos; Kallianna Dantas Araujo;

Mayara Andrade Souza; Danúbia Lins Gomes;

Ana Paula Lopes da Silva; Elba dos Santos Lira; Leila Caroline Salustiano Silva; João Gomes da Costa

Figura 2: Bacia hidrográfica do rio São Francisco, destacando-se os municípios Olho D’Água do Casado e Delmiro Gouveia, Semiárido Alagoano.

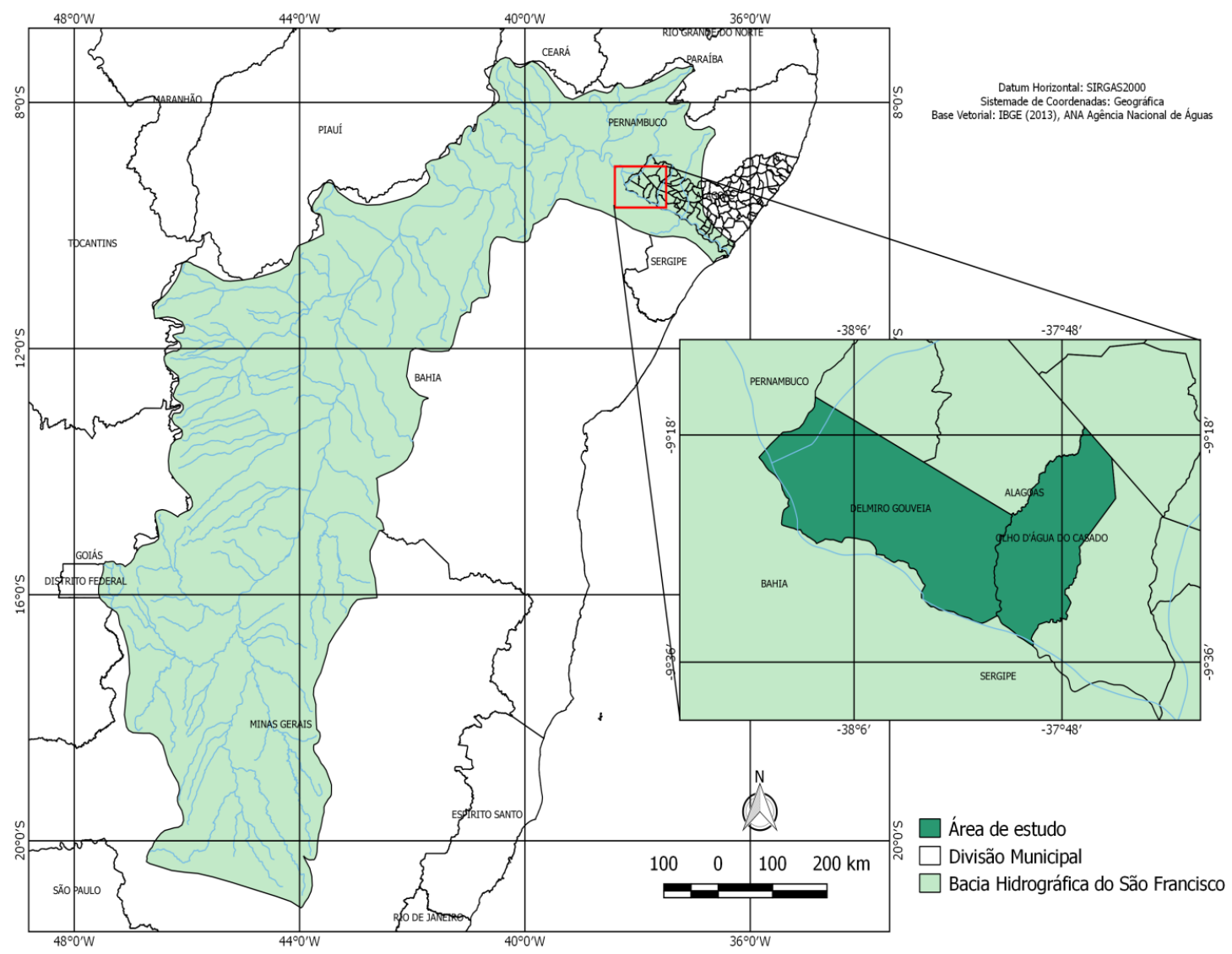

Fonte: SANTOS (2017)

A vegetação predominante nos municípios é a Caatinga Hipoxerófila com trechos de Floresta Caducifólia, sendo caracterizadas por formações xerófilas, lenhosas, decíduas e em geral espinhosas (SANTANA e SOUTO, 2006). Em levantamento florístico e fitossossiológico realizado por Souza (2011) nesses municípios foi verificada a ocorrência de espécies como Aspidosperma pyrifolium (Pereiro), Pityrocarpa moniliformis (Angelim), Tabubeia sp. (Pau d'arco), Pilosocereus gounellei (Xique-Xique), Byrsonima gardneriana (Murici), Cereus jamacaru (Mandacaru), Senna splendida (Pau de besouro), Commiphora leptophloeos (Umburana), dentre outras.

\section{Aplicação de questionários}

A pesquisa foi desenvolvida nos Assentamentos Rurais Nova Esperança (I, II e III), localizado em Olho D’Água do Casado e Maria Bonita em Delmiro Gouveia, ambos no Semiárido Alagoano. Foram aplicados 140 questionários à população local desses Assentamentos Rurais, nos quais as informações obtidas nos questionários estão focadas no aspecto social, visando obter informações sobre a forma de armazenamento de água das chuvas (se armazenam e onde armazenam), principal fonte de água utilizada pelos moradores e tipos de abastecimento domiciliar (como a água chega às residências dos moradores locais).

Cabe mencionar que mesmo com a presença de agentes comunitários de saúde nos locais, ainda são necessárias informações sobre os cuidados relacionados ao armazenamento da água, de modo a evitar os problemas saúde pública como proliferação de insetos vetores de doenças, contato com água contaminada e doenças relacionadas com parasitas.

\begin{tabular}{llllll}
\hline Caminhos de Geografia & Uberlândia - MG & v. 19, n. 68 & Dez/2018 & p. 132-142 Página 136
\end{tabular}


Alternativas de armazenamento e abastecimento de água em assentamentos rurais do semiárido alagoano
Élida Monique da Costa Santos; Kallianna Dantas Araujo;

Mayara Andrade Souza; Danúbia Lins Gomes;

Ana Paula Lopes da Silva; Elba dos Santos Lira; Leila Caroline Salustiano Silva; João Gomes da Costa

O número de questionários aplicados foi baseado na metodologia de amostragem de Rocha (1997), pela equação:

$$
\mathrm{n}=\frac{0,96 \times \mathrm{N}}{[0,01 \times(\mathrm{N}-1)+0,96]}
$$

em que:

$\mathrm{n}$ = Número de questionários aplicados;

$\mathrm{N}=$ Número total de casas na unidade considerada.

Foi considerada a mesma área de cobertura dos Agentes Comunitários de Saúde do Assentamento Rural Nova Esperança (I, II e III) e Maria Bonita (Tabela 1). Para a quantificação dos dados levantados através dos questionários aplicados, foram calculadas a frequência das respostas dos moradores, utilizando o Programa Microsoft Office Excel 2007. O questionário foi submetido e aprovado pelo Comitê de Ética da Universidade Federal de Alagoas, sob o número 49703315.0.0000.5013.

Tabela 1: Número de questionários aplicados nos Assentamentos rurais Nova Esperança I, II e III (Olho D'Água do Casado) e Maria Bonita (Delmiro Gouveia), Alagoas

\begin{tabular}{ccccc}
\hline $\begin{array}{c}\text { Agentes } \\
\begin{array}{c}\text { Comunitários } \\
\text { de Saúde }\end{array}\end{array}$ & $\begin{array}{c}\text { No de } \\
\text { residências } \\
\text { por região }\end{array}$ & $\begin{array}{c}\text { Questionários } \\
\text { aplicados } \\
(\boldsymbol{n})\end{array}$ & Propriedades Rurais & Municípios \\
\hline I & 119 & 53 & Nova Esperança I e II & Olho D'Água do Casado \\
II & 70 & 41 & Nova Esperança III & Olho D'Água do Casado \\
III & 89 & 46 & Maria Bonita & Delmiro Gouveia \\
\hline
\end{tabular}

Fonte: Os autores (2015).

\section{RESULTADOS E DISCUSSÃO}

No Assentamento Nova Esperança, em Olho D'Água do Casado, constatou-se que $69,15 \%$ dos produtores rurais armazenam água das chuvas em cisternas (Figura 3). Um percentual superior $(73,91 \%)$ foi verificado no Assentamento Rural Maria Bonita, em Delmiro Gouveia (Figura 3) no qual, muitas residências não receberam cisterna do Governo Federal, dificultando o armazenamento de grande quantidade de água das chuvas. É importante ressaltar que os moradores que não possuem cisternas particulares utilizam cisterna comunitária com distribuição de água entre as casas, mediante uso de mangueiras. Alves et al. (2012) mencionam que a utilização de cisternas para o armazenamento de água de chuva visando o consumo doméstico em áreas rurais, é uma prática que tem demonstrado eficiência como alternativas para reverter situações de falta d'água no Semiárido brasileiro. De acordo com Souza (2011), além do armazenamento de água da chuva para consumo humano, em virtude do longo período de estiagem que ocorre nesta região, há necessidade também de armazenar água para consumo animal, garantindo aos produtores a manutenção da atividade agropecuária para subsistência e/ou venda. Além disso, o procedimento de captação da água da chuva deve compreender aspectos respeito ao meio ambiente e saúde dos agricultores, destacandose uso racional de água, preservação da natureza, redução de custos da propriedade e água com padrões mínimos de qualidade (MARTINS e NOGUEIRA, 2015).

É importante enfatizar que, apesar das comunidades estudadas apresentarem essas formas de armazenamento de água das chuvas, o déficit hídrico é ainda o maior problema encontrado na região, sendo necessária a inclusão de práticas sociais que alcancem e atendam a população Semiárida da melhor maneira possível, notadamente no período de maior agravamento da escassez hídrica. Molion (1983) já destacava que o recolhimento das águas das chuvas nas pequenas propriedades poderia ser a solução para a seca no Nordeste. Este procedimento é uma técnica

$\begin{array}{llllll}\text { Caminhos de Geografia } & \text { Uberlândia - MG } & \text { v. 19, n.68 } & \text { Dez/2018 } & \text { p. 132-142 } & \text { Página } 137\end{array}$


Alternativas de armazenamento e abastecimento de água em assentamentos rurais do semiárido alagoano
Élida Monique da Costa Santos; Kallianna Dantas Araujo;

Mayara Andrade Souza; Danúbia Lins Gomes;

Ana Paula Lopes da Silva; Elba dos Santos Lira; Leila Caroline Salustiano Silva; João Gomes da Costa

utilizada desde a Antiguidade na Grécia, que sempre foi uma região muito seca, cujos templos eram construídos com os telhados inclinados para uma abertura central, no qual havia canais que transmitiam a água recolhida da chuva para as cisternas.

Figura 3: Armazenamento de água das chuvas nos Assentamento Nova Esperança I, II e III (Olho D’Água do Casado) e Maria Bonita (Delmiro Gouveia), Alagoas.

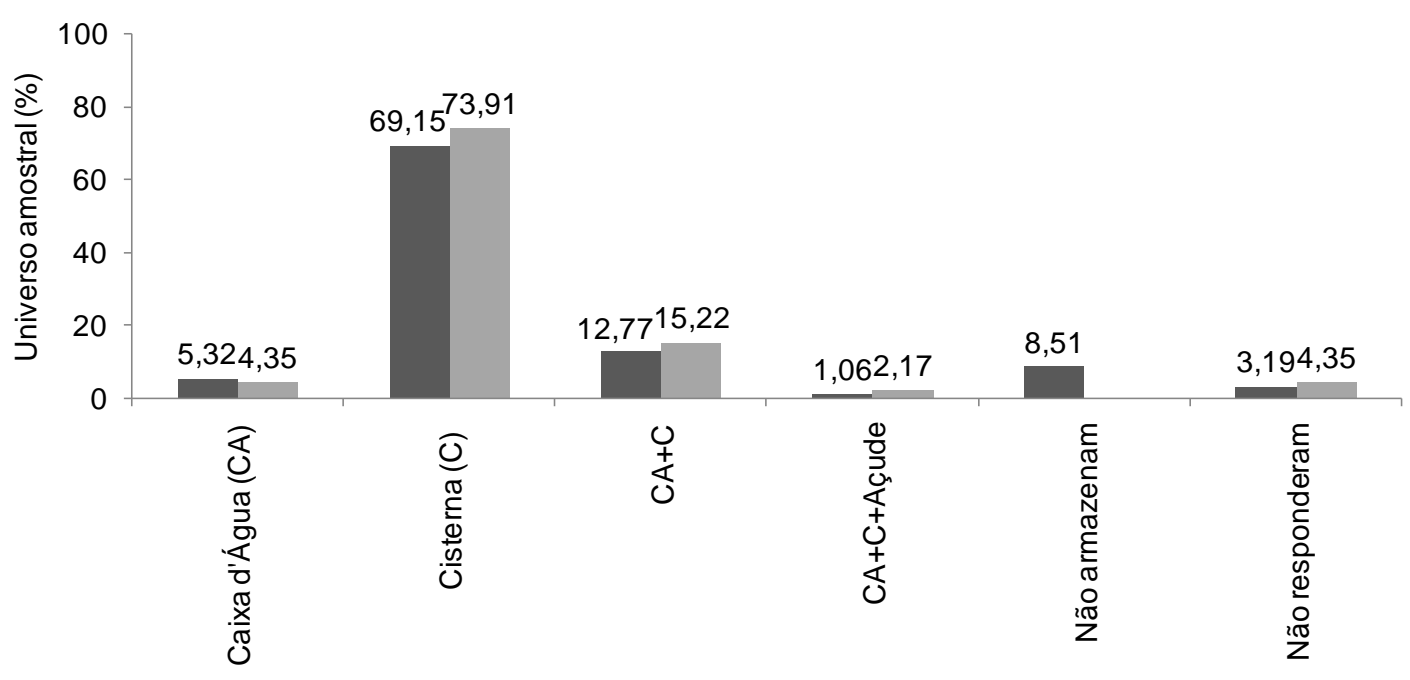

Armazenamento de água das chuvas

- Nova Esperançal, II e III Maria Bonita

Fonte: Os autores (2015)

O autor salienta ainda que a média de precipitação na região Semiárida corresponde a $400 \mathrm{~mm} / \mathrm{ano}$, o que significa 400 litros de água por metro quadrado. Desse modo, com um pequeno investimento governamental e uma área inutilizável para a agricultura em cada propriedade rural, bastando apenas impermeabilizar a área ou cobri-la com um plástico, essa água pluvial poderia ser captada, canalizada e recolhida para um reservatório. Este é um procedimento simples e barato que contribuiria para o abastecimento de águas nessas regiões, principalmente, levando em conta que alguns moradores não tem cisterna, conforme foi constatado in loco.

Desse modo, há a necessidade de obtenção de água de fontes externas como açudes e/ou rio, dificultando a vida de muitas famílias, pois é preciso se deslocar até a fonte de água, que no geral, fica distante da residência do morador. A fonte principal da água utilizada pela população é o rio São Francisco, em ambos os municípios (Figura 4), sendo $89,36 \%$ no Assentamento Rural Nova Esperança I, II e III e 86,96\% no Assentamento Maria Bonita (Figura 5). Uma parte da população é abastecida pela Companhia de Saneamento de Alagoas - CASAL, a qual os moradores pagam uma taxa mais elevada para receber uma água de qualidade. No entanto, através de conversa informal com alguns destes moradores, estes afirmaram que ainda há problemas, conforme retratado que quando houve descargas de esgotos e dejetos no rio São Francisco, cuja água recebida apresentava odor e cor alterados, ainda assim a CASAL não suspendeu o fornecimento de água aos usuários, deixando-os, vulneráveis aos riscos de doenças. De acordo com Silva et al. (2016) os municípios do Semiárido Alagoano tem como principal fonte de abastecimento de água o rio São Francisco, o que pode se tornar um problema futuro, já que poderá gerar uma sobrecarga de uso e, consequentemente, a falta deste recurso, pois, o principal problema no Semiárido, em relação à água, está ligado ao fato da demanda ser superior à oferta. Assim, o abastecimento convencional fica limitado a quem pode pagar pelos custos para obtenção de água, e além disto, há dificuldade de levar água devido às distâncias das residências, restando alternativas como cisternas, carros pipas, barreiros, dentre outros, que são importantes ferramentas de convivência com a seca.

$\begin{array}{llllll}\text { Caminhos de Geografia } & \text { Uberlândia - MG } & \text { v. 19, n. } 68 & \text { Dez/2018 } & \text { p. 132-142 } & \text { Página } 138\end{array}$


Alternativas de armazenamento e abastecimento de água em assentamentos rurais do semiárido alagoano
Élida Monique da Costa Santos; Kallianna Dantas Araujo;

Mayara Andrade Souza; Danúbia Lins Gomes;

Ana Paula Lopes da Silva; Elba dos Santos Lira; Leila Caroline Salustiano Silva; João Gomes da Costa

Figura 4: Trecho do rio São Francisco, em Olho D’Água do Casado, Alagoas.

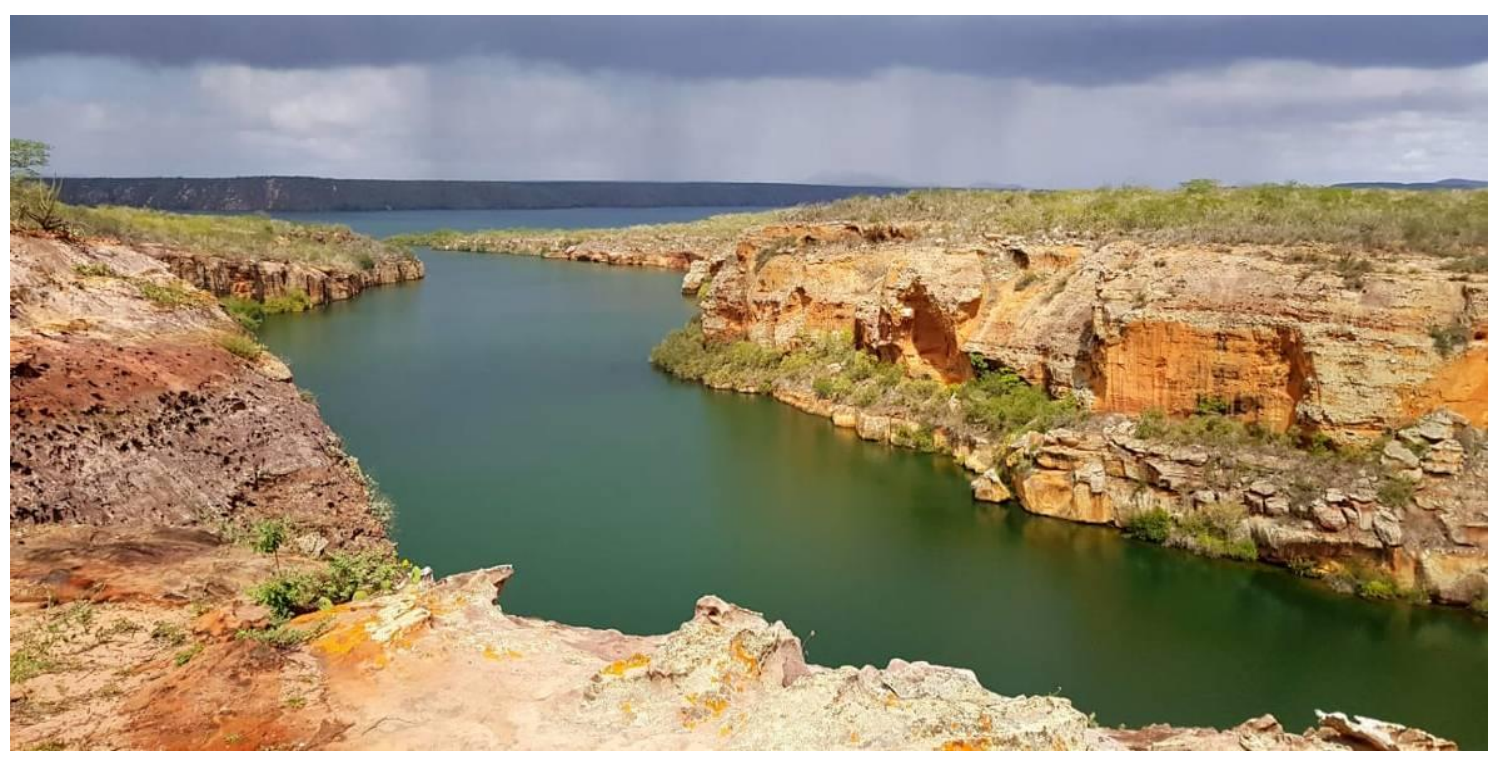

Fonte: Os autores (2018).

Figura 5: Fonte de água nos Assentamento Nova Esperança I, II e III (Olho D’Água do Casado) e Maria Bonita (Delmiro Gouveia), Alagoas.

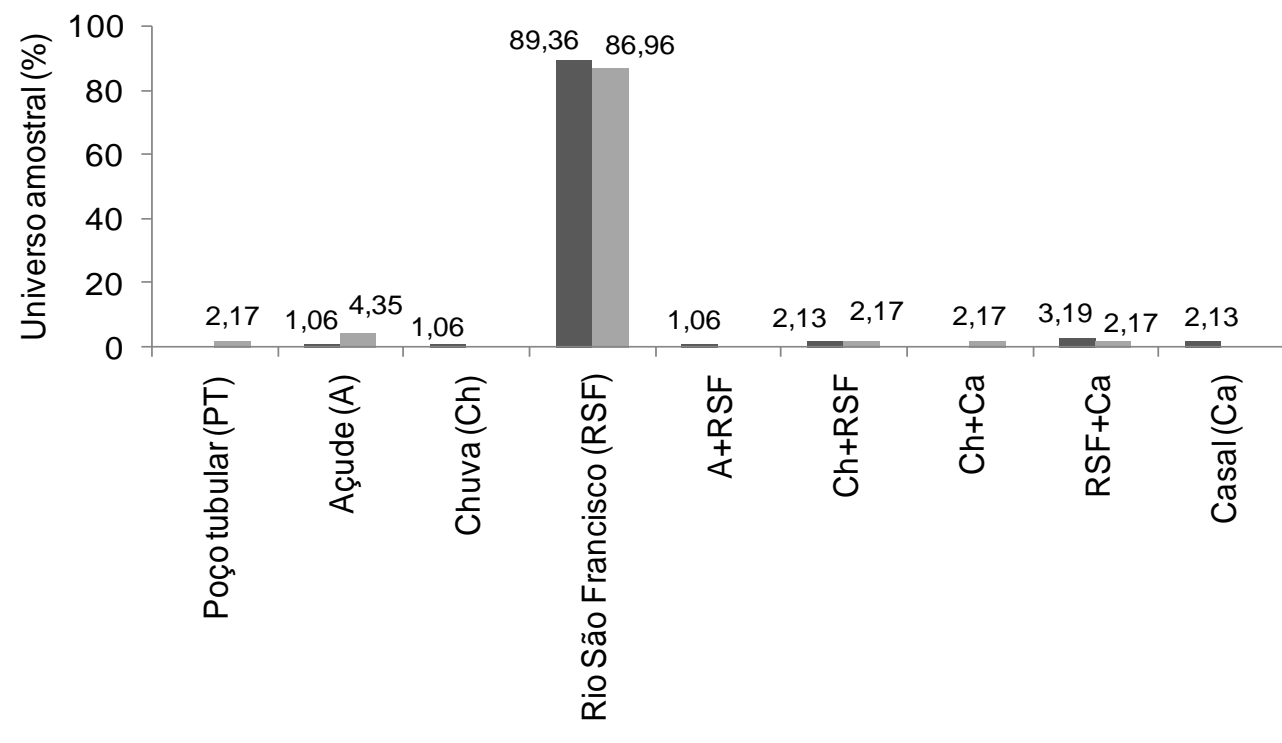

Principal fonte de água

- Nova Esperança I, II e III $\square$ Maria Bonita

Fonte: Os autores (2015).

O tipo de abastecimento domiciliar mais frequente no Assentamento Nova Esperança I, II e III $(67,02 \%)$ e Maria Bonita (67,39\%) é água encanada (Figura 6) oriunda do rio São Francisco, tanto sendo fornecida pela CASAL, como por meio de uma bomba instalada no rio São Francisco, cuja água é armazenada na cisterna de um morador local, proprietário desta bomba, e que distribui a água entre os demais moradores mediante pagamento de uma taxa de baixo valor, não recebendo, de $\begin{array}{llllll}\text { Caminhos de Geografia } & \text { Uberlândia - MG } & \text { v. 19, n. 68 } & \text { Dez/2018 } & \text { p. 132-142 } & \text { Página } 139\end{array}$ 
Alternativas de armazenamento e abastecimento de água em assentamentos rurais do semiárido alagoano
Élida Monique da Costa Santos; Kallianna Dantas Araujo;

Mayara Andrade Souza; Danúbia Lins Gomes;

Ana Paula Lopes da Silva; Elba dos Santos Lira; Leila Caroline Salustiano Silva; João Gomes da Costa

acordo com os entrevistados, nenhum tipo de tratamento químico antes de ser repassada aos demais. Durante a aplicação do questionário, alguns informaram, por meio de conversa informal, estarem apresentando problemas de saúde como febre, dores estomacais, diarréia e vômito, que são doenças típicas de veiculação hídrica e que, possivelmente, tem relação com a água recebida e utilizada por eles, como assegura Confalonieri (2010) afirmando que uma ampla parcela das doenças existentes está associada à falta de água, deficiências no esgotamento sanitário e manutenção de água de boa qualidade para as populações.

Figura 6. Forma de abastecimento domiciliar dos Assentamentos Nova Esperança I, II e III (Olho D’Água do Casado) e Maria Bonita (Delmiro Gouveia), Alagoas.

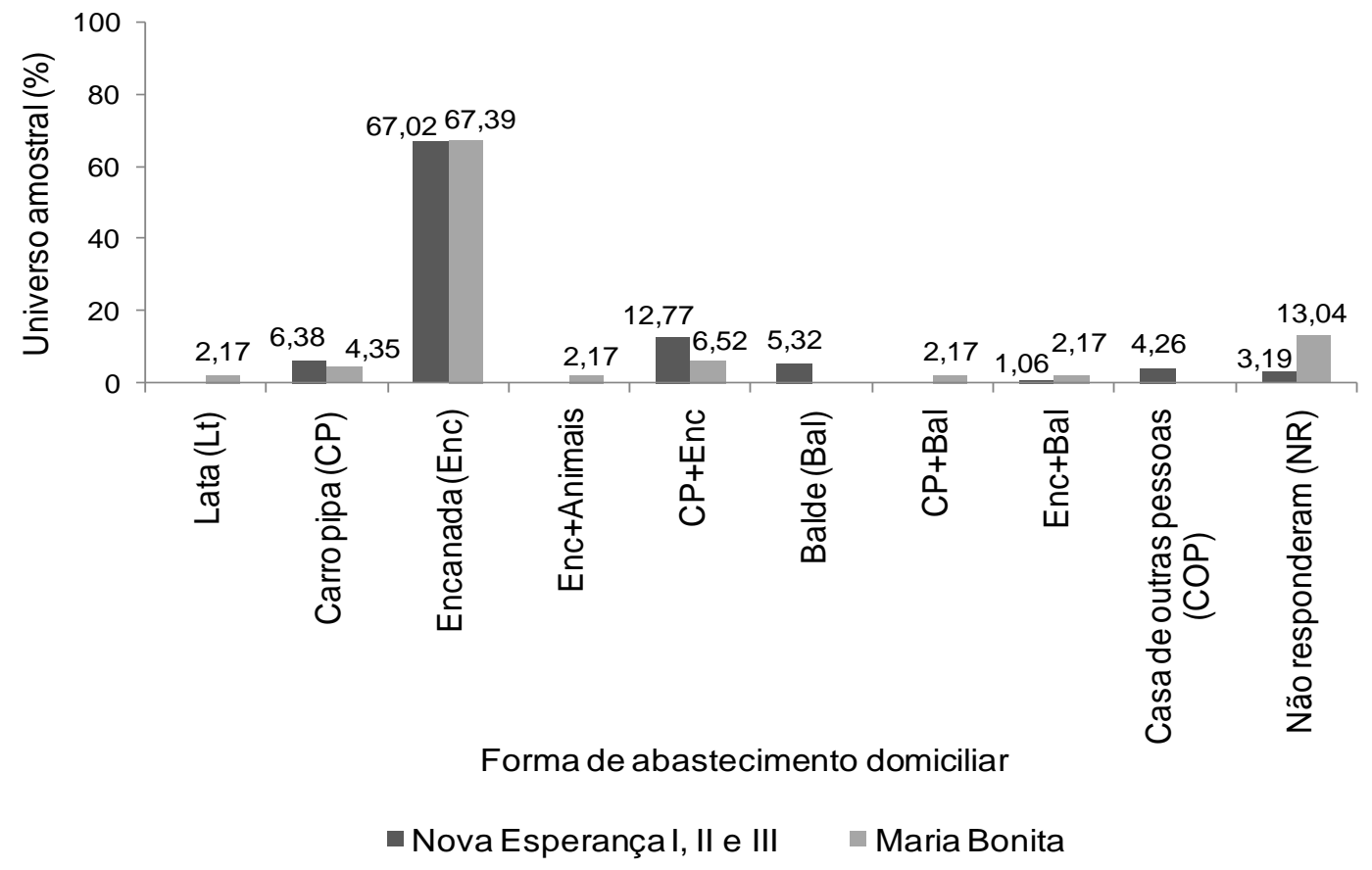

Fonte: Os autores (2015).

Alguns produtores utilizam mais de uma forma de abastecimento correspondendo a $12,77 \%$ no Assentamento Nova esperança e 6,52\% no Assentamento Maria Bonita. Estes produtores possuem água encanada e ainda assim utilizam carro pipa como forma complementar de abastecimento (Figura 6). De acordo com Andrade e Nunes (2014) o abastecimento com carro pipa foi uma medida emergencial adotada pelo Governo Federal para socorrer a população na época de estiagem que se tornou padrão nas últimas décadas do século $\mathrm{XX}$, levando em consideração que em algumas áreas onde a seca se estabelece de forma mais agravante, os habitantes locais ficam sem alternativas de obtenção de água. É uma medida usada por uma pequena parte da população, uma vez que 6,38\% dos produtores rurais no Assentamento Nova Esperança e 4,35\% no Assentamento Maria Bonita dependem do carro pipa como a única forma de abastecimento domiciliar (Figura 6), pois estes não possuem cisterna própria, nem utilizam a água da CASAL.

Os moradores também utilizam baldes e animais para transportar a água do local onde pegam até suas residências (Figura 6). Moreira (2010) destaca que nos Assentamentos Areias e Padre Alexandre Cauchi, em Porto de Pedras, Alagoas, a maioria dos Assentados usa água em suas residências provenientes de poços e cacimbas, destacando que o rio São Francisco não corta este município. Destaca-se ainda que as formas de armazenamento de água (Figura 3) e abastecimento domiciliar (Figura 6), nem sempre seguem os padrões recomendados pelo Ministério da Saúde como o tratamento da água e cobertura de água parada, além de haver ainda ausência do poder público, dentre outros, gerando condições para proliferação dos mosquitos transmissores de doenças como

$\begin{array}{llllll}\text { Caminhos de Geografia } & \text { Uberlândia - MG } & \text { v. 19, n. } 68 & \text { Dez/2018 } & \text { p. 132-142 } & \text { Página } 140\end{array}$


Alternativas de armazenamento e abastecimento de água em assentamentos rurais do semiárido alagoano
Élida Monique da Costa Santos; Kallianna Dantas Araujo;

Mayara Andrade Souza; Danúbia Lins Gomes;

Ana Paula Lopes da Silva; Elba dos Santos Lira; Leila Caroline Salustiano Silva; João Gomes da Costa

Dengue, Chikungunya e Zika. De acordo com Rabelo et al. (2015) a área mais afetada pela Dengue é na região da zona rural, pois nela há naturalmente uma maior facilidade para o crescimento do mosquito transmissor devido as condições ambientais do local, como a presença de açudes, barreiros e rios temporários.

\section{CONSIDERAÇÕES FINAIS}

- A principal fonte de abastecimento de água nos Assentamentos Nova Esperança e Maria Bonita é o rio São Francisco, no entanto a água recebida é sem tratamento, pois a maioria dos moradores não utilizam a água fornecida pela CASAL (Companhia de Saneamento de Alagoas);

- Nos dois Assentamentos a maioria da população armazena água em cisternas;

- Mesmo com água encanada em casa, os moradores fazem uso de carro-pipa para complementar o abastecimento domiciliar, notadamente no período de estiagem;

- Uma forma de minimizar os problemas causados pela estiagem no Semiárido Alagoano é tornar uma área inutilizada em um local próprio para captação e armazenamento de água pluvial de uso comunitário;

- Sugere-se a realização de testes físicos, químicos e biológicos da água para análise da qualidade da mesma recebida pelos moradores desta região.

\section{AGRADECIMENTOS}

À CAPES pela concessão da bolsa de estudo para a realização desta pesquisa; Ao Programa de Pós-Graduação em Geografia; Ao Laboratório de Ecogeografia e Sustentabilidade AmbientalLabESA, pelo auxílio no levantamento de dados em campo.

\section{REFERÊNCIAS}

ALAGOAS. Secretaria de Estado do Planejamento e Desenvolvimento Econômico. Perfil municipal: Olho D’Água do Casado. Maceió. 2015. (a).

Perfil municipal: Delmiro Gouveia. Maceió. 2015. (b).

ALVES, D. F. da S. et al. Análise do processo de armazenamento de água de chuva em cisternas de placas e sua utilização no município de Tavares, estado da Paraíba. In: VII CONGRESSO NORTE NORDESTE DE PESQUISA E INOVAÇÃO, 7, 2012, Palmas, Anais... Palmas: CONNEPI, 2012. p. 18.

AL-SALAYMEH, A.; AL-KHATIB, I. A.; ARAFAT, H. A. Towards Sustainable Water Quality: Management of Rainwater Harvesting Cisterns in Southern Palestine. Water Resour Management, v. 25, p. 1721-1736, 2011. https://doi.org/10.1007/s11269-010-9771-0

ANDRADE, J. A. de; NUNES, M. A. Acesso à água no Semiárido Brasileiro: uma análise das políticas públicas implementadas na região. Revista Espinhaço, v. 3, p. 28-39, 2014.

CASTRO, R. Educação ambiental, valorização de diversidades. Revista do Instituto Humanitas Unisinos, ano XXII, p. 20-23, 2012.

CONFALONIERI, U. Água e saúde: Aspectos Globais e Nacionais. In: BICUDO, C. E. M. et al. Águas do Brasil: análises estratégicas. 1. ed. São Paulo: Instituto de Botânica, 2010. 224 p.

DRUMOND, M. A. Caatinga: Bioma rico em diversidade. Revista do Instituto Humanitas Unisinos, ano XII, p. 13-17, 2012.

Empresa Brasileira de Pesquisas Agropecuárias - EMBRAPA. Solos do Município de Olho D’Água do Casado: Estado de Alagoas. 1. ed. Rio de Janeiro: Embrapa Solos, 2007. 4 p. (Comunicado Técnico).

EMPRESA BRASILEIRA DE PESQUISAS AGROPECUÁRIAS - EMBRAPA. Zoneamento agroecológico do Estado de Alagoas: Levantamento de reconhecimento de baixa e média intensidade dos solos do Estado de Alagoas. 1. ed. Rio de Janeiro: Embrapa Solos, 2012. 238 p.

$\begin{array}{llllll}\text { Caminhos de Geografia } & \text { Uberlândia - MG } & \text { v. 19, n. } 68 & \text { Dez/2018 } & \text { p. 132-142 } & \text { Página } 141\end{array}$


Alternativas de armazenamento e abastecimento de água em assentamentos rurais do semiárido alagoano
Élida Monique da Costa Santos; Kallianna Dantas Araujo; Mayara Andrade Souza; Danúbia Lins Gomes;

Ana Paula Lopes da Silva; Elba dos Santos Lira; Leila Caroline Salustiano Silva; João Gomes da Costa

LACERDA, M. A. de. et al. Potencial forrageiro da jitirana (Merremia Aegyptia) para a produção de feno no Semiárido nordestino. Revista Agropecuária Científica no Semiárido, v.11, p. 44-52, 2015.

LIMA, I. F. Fundamentos geográficos do meio físico do Estado de Alagoas. 1. ed. Maceió: Governo do Estado de Alagoas/SEPLAN/SUDENE, 1977. (Série: Estudo de Regionalização).

MARENGO, J. A. et al. Variabilidade e mudanças climáticas no Semiárido brasileiro. In: MEDEIROS, $\mathrm{S}$. de $\mathrm{S}$. et al. Recursos hídricos em regiões áridas e semiáridas. Campina Grande: Instituto Nacional do Semiárido, 2011. p. 383-422.

MARENGO, J. A. Vulnerabilidade, impactos e adaptação à mudança do clima no semi-árido do Brasil. Parcerias Estratégicas, v. 13, p. 1-28, 2008.

MARTINS, C. A. S.; NOGUEIRA, N. O. Captação de água da chuva em propriedades rurais. Nucleus, v. 12, p. 87-106, 2015. https://doi.org/10.3738/1982.2278.1342

MASCARENHAS, J. de C.; BELTRÃO, B. A., SOUZA JUNIOR, L. C. de. Projeto cadastro de fontes de abastecimento por água subterrânea: diagnóstico do município de Olho D' Água do Casado, estado de Alagoas. Recife: CPRM/PRODEEM, 2005. 12 p. a

Projeto cadastro de fontes de abastecimento por água subterrânea: diagnóstico do município de Delmiro Gouveia, estado de Alagoas. Recife: CPRM/PRODEEM, 2005. 12 p. b

MENDONÇA, C. A. P.; SIMÕES, L. Enciclopédia dos municípios alagoanos. 2. ed. Maceió: Núcleos de Projetos Especiais, Instituto Arnon de Mello, 2012.

MOREIRA, J. C. G. Perfil socioeconômico e ambiental dos produtores rurais dos

Assentamentos do Município de Porto de Pedras, em Alagoas. Monografia (Graduação em Agronomia) - Rio Largo: UFAL. 2010.

NADDEO, V.; SCANNAPIECO, D.; BELGIOMO, V. Enhanced drinking water supply through harvested rainwater treatment. Journal of Hidrology. v. 498, p. 287-291, 2013.

https://doi.org/10.1016/j.jhydrol.2013.06.012

RABELO, F. L. G. et al. Prevalência de dengue no município de Morada Nova-CE. In: MOSTRA CIENTÍFICA DE FARMÁCIA, 1, 2015, Quixadá, Anais... Quixadá: FCRS Católica de Quixadá, 2015. $2 \mathrm{p}$.

SAMPAIO, E. V. de S. B. Características e potencialidades. In: GARIGLIO, M.A. et al. Uso sustentável e conservação dos recursos florestais da Caatinga. Brasília: Serviço Florestal Brasileiro, 2010. p. 29-42.

SANTANA, J. A. da S.; SOUTO, J. S. Diversidade e estrutura fitossociológica da caatinga na Estação Ecológica do Seridó-RN, Revista de Biologia e Ciências da Terra, v. 6, p. 232-242, 2006.

SANTOS, J. M. et al., Seca, precipitação e captação de água de chuva no semiárido de Sergipe. Engenharia Ambiental, v. 6, p. 055-073, 2009.

SEYFFARTH, J. A. Semiárido, o bioma mais diverso do mundo. Revista do Instituto Humanitas Unisinos, ano XII, p. 9,10, 2012.

SILVA, L. C. S. et al., Importância das nascentes do Semiárido Alagoano no abastecimento das populações rurais difusas. Revista de Geociências do Nordeste, v. 2, p.534-544, 2016.

SOARES, K. A. B. Perfil do uso da lenha no ramo de produtos alimentícios na cidade de Patos PB. Dissertação (Mestrado em Ciências Florestais) - Campina Grande: UFCG. 2011.

SOUZA, M. A. Fitossociologia em áreas de caatinga e conhecimento etnobotânico do murici (Byrsonima gardneriana A. Juss.), Semiárido Alagoano. Dissertação (Mestrado em Agronomia) Areia: UFPB. 2011.

UFCG - UNIVERSIDADE FEDERAL DE CAMPINA GRANDE. Dados climatológicos do Estado de Alagoas. 2017. Disponível em: <http//www.dca.ufcg.edu.br> Acesso em: 17 de outubro de 2017.

Recebido em: 31/10/2017

Aceito para publicação em: 27/08/2018

$\begin{array}{llllll}\text { Caminhos de Geografia } & \text { Uberlândia - MG } & \text { v. 19, n. } 68 & \text { Dez/2018 } & \text { p. 132-142 } & \text { Página } 142\end{array}$

